\title{
Plastic or Metal Stents for Transmural Drainage of Pancreatic Fluid Collections
}

Acute pancreatitis is a disease of varying severity and associated with various local and systemic complications. Peripancreatic fluid collections are an important local complications of acute pancreatitis and have been recently subdivided into four broad categories by the revised Atlanta classification as follows: ${ }^{[1]}$ Acute pancreatic fluid collection: fluid collection in nonnecrotizing pancreatitis within 4 weeks of onset of pain; pancreatic pseudocyst (PC): fluid collection with well-formed wall in nonnecrotizing pancreatitis after 4 weeks of onset of pain; acute necrotic collection: fluid collection in necrotizing pancreatitis within 4 weeks of onset of pain; and walled-off necrosis (WON): fluid collection with well-formed wall in necrotizing pancreatitis after 4 weeks of onset of pain. The symptomatic WON or PC need some form of drainage procedure either by endoscopic, interventional radiological, or surgical approach. With the advances in endoscopic techniques, minimally invasive endoscopic procedure, particularly endoscopic ultrasound (EUS)-guided transmural drainage through stomach or duodenum, is now the mainstay of treatment of symptomatic walled-off pancreatic fluid collections. ${ }^{[2]}$

EUS-guided transmural drainage of pancreatic fluid collections was earlier done by double-pigtail plastic stents (DPPSs). The plastic stent was able to achieve drainage of the fluid component effectively and thus PCs could be safely and effectively treated with one or more transmural plastic stents. However, this strategy was not effective in WON as the plastic stents were not able to effectively drain the solid necrotic component. ${ }^{[3-5]}$ To overcome this problem, either multiple plastic stents or a larger diameter fully covered metal stent are being used for the drainage of WON. ${ }^{[6,7]}$

With the development of dedicated metal stents for WON drainage like lumen-apposing metal stent (LAMS) like Axios stent (Boston Scientific, Natick, MA, USA) or biflanged metal stent (BFMS) like Nagi stent (Taewoong Medical, Gyeonggi-do, South Korea), the management of pancreatic fluid collections with lots of solid debris has become easier. These stents are fully covered and easy to deploy with high rate technical success. Moreover, it is easy to perform direct endoscopic necrosectomy (DEN) through the stent whenever, required. However, the metal stents are costly and have their own set of complications such as bleeding, stent migration, and blockage of stent lumen by necrotic material. Direct comparative studies looking at safety and efficacy between plastic and metal stents for drainage of PFC are lacking. In this news and views, we will discuss two different studies in different centers in the USA comparing the outcome of plastic versus metal stent in the management of pancreatic fluid collections published recently. The first study is by Abu Dayyeh et al. who compared the outcome of endoscopic management of WON using a large caliber BFMS versus DPPSs in 94 patients. $^{[8]}$ The second study is by Lang et al. who compared the efficacy of drainage of PPFC (both PC and WON) by LAMS versus DPPSs in 103 patients. ${ }^{[9]}$

Abu Dayyeh et al. retrospectively evaluated 94 patients with WON who underwent EUS-guided drainage. ${ }^{[8]}$ The drainage was done by standard technique with a 19-gauge needle to make the cystogastrostomy/cystoduodenostomy tract. Fifty-eight patients received a large caliber fully covered self-expanding metal stent (LC-SEMS) either a $15 \mathrm{~mm}$ diameter LAMS (Axios; Boston Scientific) or a $6 \mathrm{~cm}$ long and 18 or $20 \mathrm{~mm}$ diameter tubular LC-SEMS (Niti-S; Taewoong Medical). Thirty-six patients received 2 or more $7 \mathrm{~F}$ or 10F DPPSs. Few patients underwent initial DEN at the time of initial endoscopy. Subsequent DEN was performed if remaining solid material was more than $80 \%$ by visual inspection or the WON does not decrease by $>50 \%$ in subsequent scheduled cross-sectional imaging, or if the patient had persistent symptoms infection or gastric outlet obstruction with the presence of residual WON. DEN was performed by entering the WON cavity with a standard or therapeutic channel endoscope followed by mechanical debridement of necrotic material using irrigation, cap suction, snares, baskets, forceps, or a combination of these. Dilute hydrogen peroxide was instilled during endoscopic transmural necrosectomy in some cases. Some patients also underwent concomitant percutaneous drainage.

The mean size of WON was $6.5 \mathrm{~cm}$ and $5.8 \mathrm{~cm}$ in LC-SEMS and DPPS group, respectively. Overall rate of WON resolution was $93.6 \%$ when concomitant percutaneous drainage was not considered failure of endoscopic management and $79.8 \%$ when concomitant percutaneous drainage was considered a failure of transmural drainage. Median time to WON resolution overall was 8 weeks (interquartile range 6-12 weeks). There was no difference in WON resolution rate or time to WON resolution between the DPPSs and LC-SEMS. The size and location of the WON also did not influence the WON resolution rate between the two groups. Even when the comparison was made between the LAMS and DPPS, there was no difference in the rate of and time required to WON resolution. However, when transmural 
drainage was done without a subsequent DEN procedure, WON resolution was more frequent in LC-SEMS group as compared to DPPS group (60.4\% vs. $30.8 \%, P=0.01)$. In patients with larger WON $(>13 \mathrm{~cm})$, resolution rate decreased to $40 \%$ and $10 \%$ for LC-SEMS and DPPS, respectively, without subsequent DEN. Higher resolution of WON was also there in LC-SEMS group when DPPS was compared only with LAMS (odds ratio $[\mathrm{OR}]=4.1$, 95\% confidence interval [CI], 1.46-12.7). With subsequent DEN procedure, the number of DEN required in LC-SEMS group was lower than DPPS group, but the difference did not reach significance level $(P=0.12)$. The hospital stay and Intensive Care Unit stay were lower in LC-SEMS group as compared to DPPS group. Most of the adverse events were similar in both the groups except for the clinically significant bleeding requiring endoscopic intervention which was higher in DPPS group as compared to SEMS group $(14 \%$ vs. $2 \% P=0.02)$. Rate of perforation, stent migration, and stent occlusion were similar in both the groups. When tubular LC-SEMS was compared with LAMS, there was no difference in outcome variables. The authors concluded that endoscopic drainage of pancreatic WON with LC-SEMSs appears to decrease both the need for repeated DEN as well as the risk of intervention-related hemorrhage.

Lang et al. retrospectively evaluated 103 patients (mean age 51.6 years, $60 \%$ male) with PPFC (WON or PC) who underwent EUS-guided drainage. ${ }^{[7]}$ In this study, either plastic double-pigtail stents (7F or 10F Cook Medical, Winston-Salem, NC, USA) or LAMS (AXIOS, Boston Scientific; Marlborough, MA, USA) were deployed in 84 and 19 patients, respectively, for transmural drainage. The number of DPPSs, size of LAMS (10 or $15 \mathrm{~mm}$ ), need for initial debridement, balloon dilatation of the LAMS, and whether or not a DPPS was placed through the LAMS were determined by the physician performing the procedure. A cross-sectional imaging was done within 2-4 weeks postprocedure to assess the response. Stents were removed at a time period determined by the physician performing the procedure after resolution of PPFC. Some patients also underwent ERCP and pancreatic duct stenting at the discretion of the physician.

Eighty (78\%) patients had PC whereas 23 (22\%) patients had WON. The mean diameter of PPFCs was $88 \mathrm{~mm}$ (range $41-178 \mathrm{~mm}$ ) and $104 \mathrm{~mm}$ (range $67-155 \mathrm{~mm}$ ) in DPPS and LAMS group, respectively. Median number of DPPS placed were 2 (range: 1-3). Initial DEN was performed in 3 patients in DPPS and 2 patients in LAMS group whereas subsequent DEN was performed in 1 patient in DPPS and 13 in LAMS group. Overall clinical success rate, determined by complete resolution of the PPFC within 6 months, was $95 \%$ (96\% in DPPS and 94\% in LAMS) with the difference being not significant. Adverse events were also higher in LAMS group (53\%) as compared to the DPPS group (12\%). Among all the adverse events including perforation, bleeding, and requirement of unplanned endoscopy, bleeding was significantly higher in LAMS group $(P=0.0003)$ compared to DPPS, and there was a trend toward significance in higher need for unplanned endoscopy in LAMS group $(P=0.07)$. Bleeding was $1 \%$ in DPPS group and $21 \%$ in LAMS group (OR - 22.1; 95\% CI 2.3-211.9). Bleeding in DPPS group was due to stent eroding the opposite gastric wall around 30 days after its insertion. In LAMS group, one case of bleeding was due to intracavitary vessel bleed, one was due to injury to collateral during insertion, and in two patients, the bleeding was due to bleeding from splenic artery pseudoaneurysm. Stent obstruction by necrotic material was seen in $5(56 \%)$ patients. Four of these patients underwent subsequent DDPS placement through LAMS and these patients did not develop further stent block. The authors concluded that both DPPSs and LAMSs are effective methods for treatment of PPFCs and in their cohort of patients, LAMS were associated with significantly higher rates of procedure-related bleeding and greater need for repeat endoscopic intervention.

\section{COMMENTARY}

The management of pancreatic fluid collection developing after acute pancreatitis has evolved greatly in recent times from major morbid surgical necrosectomy to minimally invasive percutaneous radiological interventions and endoscopic transmural drainage. Although endoscopic transmural drainage is now the preferred modality of treatment for pseudocysts as well as WONs, the choice of stents for ransmural drainage in WON is a debatable topic. Few studies that have compared the plastic and metal stents for treatment of WON have shown conflicting results in terms of efficacy and adverse events. ${ }^{[10-13]}$

Theoretically larger diameter of the metal stents would allow passage of solid material more easily as compared to narrower diameter of plastic stents. However, a recent retrospective case-control study found no significant difference in treatment success, reinterventions, clinical and stent-related adverse events between patients treated with LAMS versus plastic stents. ${ }^{[14]} \mathrm{A}$ recent meta-analysis published in an abstract form reported that metal stents are equally effective in draining PC and WON but have better clinical success rate in draining WON as compared to plastic stents. ${ }^{[15]}$ Similarly, both the studies discussed above have demonstrated equal efficacy of both plastic and metal stents in treating pancreatic fluid collections. Furthermore, for removal of solid necrotic debris, patients 
treated with plastic stents will require more sessions of DEN as compared to metal stents as shown by Abu Dayyeh et al. With the use of metal stents, DEN becomes easier and number of re-interventions required are also less. However, necrotic solid material can clog the lumen of the metal stent after draining the fluid component. Putting a plastic stent through the metal stent may prevent this complication as shown by Lang et al. Among the metal stents, the specially designed LAMS have not been shown to be more effective then tubular LC-SEMS in most studies including the two studies discussed here. Regarding the adverse outcomes of plastic versus metal stents, different studies have shown different results, some showing more adverse events with plastic stents and some showing otherwise and the same has been the trend in the two studies discussed here. Bleeding has been shown to be more common with metal stents as compared to plastic stents in most studies. However, the study by Abu Dayeeh et al. discussed above has shown more bleeding episodes with plastic stents. Metal stents cause rapid decompression of the PPFC and thus causing shrinkage of the WON cavity leading bleeding. In spite of increasing number of studies available looking at the safety and efficacy of plastic versus metal stents in the treatment of pancreatic WON, because of the differing results and conclusions, the final verdict on the choice of stents is still not out. The final answer to this management dilemma will be probably answered by a multicentric prospective comparative randomized study only.

\section{Sobur Uddin Ahmed, Surinder Singh Rana}

Department of Gastroenterology, Postgraduate Institute of Medical Education and Research, Chandigarh, India

Address for correspondence: Dr. Surinder Singh Rana, Department of Gastroenterology, Postgraduate Institute of Medical Education and Research, Chandigarh - 160 012, India. E-mail: drsurinderrana@yahoo.co.in

\section{REFERENCES}

1. Banks PA, Bollen TL, Dervenis C, Gooszen HG, Johnson CD, Sarr MG, et al. Classification of acute pancreatitis-2012: Revision of the Atlanta classification and definitions by international consensus. Gut 2013;62:102-11.

2. Rana SS, Sharma V, Sharma R, Gupta R, Bhasin DK. Endoscopic ultrasound guided transmural drainage of walled off pancreatic necrosis using a "step-up" approach: A single centre experience. Pancreatology 2017;17:203-8.

3. Rana SS, Bhasin DK, Sharma RK, Kathiresan J, Gupta R. Do the morphological features of walled off pancreatic necrosis on endoscopic ultrasound determine the outcome of endoscopic transmural drainage? Endosc Ultrasound 2014;3:118-22.

4. Baron TH, Harewood GC, Morgan DE, Yates MR. Outcome differences after endoscopic drainage of pancreatic necrosis, acute pancreatic pseudocysts, and chronic pancreatic pseudocysts. Gastrointest Endosc 2002;56:7-17.

5. Holt BA, Varadarajulu S. The endoscopic management of pancreatic pseudocysts (with videos). Gastrointest Endosc
2015;81:804-12.

6. Varadarajulu S, Bang JY, Phadnis MA, Christein JD, Wilcox CM. Endoscopic transmural drainage of peripancreatic fluid collections: Outcomes and predictors of treatment success in 211 consecutive patients. J Gastrointest Surg 2011;15:2080-8.

7. Rana SS, Bhasin DK, Rao C, Gupta R, Singh K. Non-fluoroscopic endoscopic ultrasound-guided transmural drainage of symptomatic non-bulging walled-off pancreatic necrosis. Dig Endosc 2013;25:47-52.

8. Abu Dayyeh BK, Mukewar S, Majumder S, Zaghlol R, Vargas Valls EJ, Bazerbachi F, et al. Large-caliber metal stents versus plastic stents for the management of pancreatic walled-off necrosis. Gastrointest Endosc 2017. pii: S0016-510731857-6.

9. Lang GD, Fritz C, Bhat T, Das KK, Murad FM, Early DS, et al. EUS-guided drainage of peripancreatic fluid collections with lumen-apposing metal stents and plastic double-pigtail stents: Comparison of efficacy and adverse event rates. Gastrointest Endosc 2017. pii: S0016-510732077-1.

10. Lee BU, Song TJ, Lee SS, Park DH, Seo DW, Lee SK, et al. Newly designed, fully covered metal stents for endoscopic ultrasound (EUS)-guided transmural drainage of peripancreatic fluid collections: A prospective randomized study. Endoscopy 2014;46:1078-84.

11. Mukai S, Itoi T, Baron TH, Sofuni A, Itokawa F, Kurihara T, et al. Endoscopic ultrasound-guided placement of plastic vs. biflanged metal stents for therapy of walled-off necrosis: A retrospective single-center series. Endoscopy 2015;47:47-55.

12. Sharaiha RZ, DeFilippis EM, Kedia P, Gaidhane M, Boumitri C, Lim HW, et al. Metal versus plastic for pancreatic pseudocyst drainage: Clinical outcomes and success. Gastrointest Endosc 2015;82:822-7.

13. Siddiqui AA, Kowalski TE, Loren DE, Khalid A, Soomro A, Mazhar SM, et al. Fully covered self-expanding metal stents versus lumen-apposing fully covered self-expanding metal stent versus plastic stents for endoscopic drainage of pancreatic walled-off necrosis: Clinical outcomes and success. Gastrointest Endosc 2017;85:758-65.

14. Bang JY, Hasan MK, Navaneethan U, Sutton B, Frandah W, Siddique $\mathrm{S}$, et al. Lumen-apposing metal stents for drainage of pancreatic fluid collections: When and for whom? Dig Endosc 2017;29:83-90.

15. Hammad TA, Khan MA, Sharaiha RZ, Tyberg A, Alastal Y, Haq K, et al. Efficacy and safety of lumen-apposing metal stents in EUS guided transmural drainage of pancreatic fluid collections: Are they better than multiple plastic stents? A systematic review and meta-analysis. Gastrointest Endosc 2017;85:AB214.

This is an open access article distributed under the terms of the Creative Common Attribution-NonCommercial-ShareAlike 3.0 License, which allows others to remix, tweak, and build upon the work non-commercially, as long as the author is credited and the new creations are licensed under the identical terms.

\begin{tabular}{|l|l|}
\hline \multicolumn{2}{c}{ Access this article online } \\
\hline Quick Response Code: & Website: www.jdeonline.in \\
\hline
\end{tabular}

How to cite this article: Ahmed SU, Rana SS. Plastic or metal stents for transmural drainage of pancreatic fluid collections. J Dig Endosc $2017 ; 8: 150-2$. 